\title{
Lower Urinary Tract Symptoms Before and After Simple Abdominal Hysterectomy in a Selected Tertiary Hospital
}

\author{
MS JAHAN ${ }^{\mathrm{a}}$, SMB BILLAH ${ }^{\mathrm{b}}$
}

\begin{abstract}
Summary:
Objective: To assess lower urinary tract symptoms (LUTS) before and after simple abdominal hysterectomy. Methods: This quasi-experimental study was conducted in Bangabandhu Sheik Mujib Medical University, Dhaka on respondents who were waiting for simple abdominal hysterectomy for beneign gynaecological problems. LUTS and ultrasonic and uroflowmetric findings were assessed on 48 patients before simple abdominal hysterectomy (SAH) followed by reassessment of symptoms on 33 patients and uroflowmetric assessment on 27 patients within 3-4 months after SAH. Results: Thirty percent urgency $(p=0.02), 18 \%$ urge incontinence $(p=0.03), 42 \%$ stress incontinence $(p=0.001), 24 \%$ dysuria (0.02), 33\% stress on cough or vulsalva $(p=0.001), 27 \%$ delayed bladder emptying $(p=0.04)$ and $30 \%$ sensation of residual urine $(0.01)$ was improved significantly after $\mathrm{SAH}$ while around $18 \%$ urinary frequency
\end{abstract}

Introduction:

With whatever the route preferred for hysterectomy ${ }^{1}$, the consequences of the surgery commonly take its toll on urinary and sexual morbidities. Studies ${ }^{2}$ show $75 \%$ vaginal hysterectomy (VH), 12\% laparoscopic assisted vaginal hysterectomy (LAVH), and 10\% abdominal hysterectomy (AH) patients suffer from peri and post operative complications. Many women in gynecological and urological clinics with debilitating urinary symptoms complaining of onset to previous hysterectomy ${ }^{3-5}$. Urinary dysfunction following radical hysterectomy (RH) has been evident by Ralph ${ }^{6}$ et al. The complications are wide ranging; i.e. voiding by abdominal straining, impairment of bladder sensation, alteration of bladder capacity and compliance, detrusor

a. Dr. Muna Shalima Jahan, Associate Professor, Department of Obstetrics and Gynaecology, Sir Salimullah Medical College \& Mitford Hospital, Dhaka.

b. Dr. Syed Muhammad Baqui Billah, Department of Community Medicine, Sher-e Bangla Medical College, Barisal.

Address of Correspondence: Dr. Muna Shalima Jahan, Associate Professor, Department of Obstetrics and Gynaecology, Sir Salimullah Medical College \& Mitford Hospital, Dhaka, Tel: +81-(0)-463-931121, Email: shalimajm@gmail.com

Received: 10 September, 2013

Accepted: 15 October, 2014 $(p=0.07)$ was almost significantly improved. None of the patients complained of nocturia after SAH. As for urodynamic assessment, there was significant increase in maximum bladder capacity $(\boldsymbol{p}<0.001)$, decrease in bladder wall thickness $(p<0.001)$ and decrease in average flow rate (0.04) though there was no significant decrease in post void residue. Overall there had been a considerable decrease of all pre operative symptoms from nearly $82 \%$ to $37 \%$ post operatively. Conclusions: There was significant improvement of voiding symptoms following $\mathrm{SAH}$ as well as improvement of ultrasongraphic findings and uroflometric features.

Key Words: Voiding Function, Simple Hysterectomy, Lower Urinary Tract, Incontinence.

(J Banagladesh Coll Phys Surg 2015; 33: 7-11)

function compromise, reduction of maximum urethral pressure and/or maximum urethral closure pressure, neurological problems leading to change in urinary tract function, even intrinsic sphincter deficiency resulting in urinary incontinence (UI) ${ }^{5,7-12}$. On the contrary, some studies did not find any urinary complains ${ }^{13}$, rather a significant decrease in urinary complains and residual bladder volume after surgery ${ }^{14-16}$ were observed. Again some studies find no association ${ }^{17,18}$ with the routes of hysterectomy and urinary or sexual function, rather there had been substantial improvement ${ }^{19}$ of urinary symptoms following hysterectomy.

As hysterectomy is a common practice for management for gynecological patients in every country as well as in Bangladesh, the scan of the scenario needed to be done which was felt by the researcher to get into the study process. Even in our country the patients usually don't disclose any urinary symptoms out of shyness unless it goes way beyond endurance. The researcher's objective was to identify, any lower urinary tract symptoms along with the diagnosed problem before the intended surgery which patients are otherwise reluctant to disclose to the healthcare providers and to measure any change of voiding function after the procedure. The primary null 
hypothesis of the study was that there is no effect on lower urinary tract functions following simple abdominal hysterectomy (SAH).

\section{Methodology:}

This quasi experimental study assessed voiding functions of patients waiting for simple abdominal hysterectomy (SAH) for one or other of the benign gynaecological indications, before and after the surgery from January 2004 to December 2005 at Bangbandhu Sheikh Mujib Medical University. Those patients who were diagnosed with any of the gynaecological malignancies were excluded from the study. After taking informed written consent, the demographic variables like age, parity, menstrual status and indication of operation for hysterectomy were recorded before SAH. This was followed by recording of the lower urinary tract symptoms(LUTS) related to voiding such as frequency, nocturia, urgency, urge incontinence, stress incontinence, dysuria, stress on cough of vulsalva, bladder emptying and sensation of residual urine, if any. Moreover, the ultrasonographic features and findings with uroflowmetry like, maximum bladder capacity, bladder wall thickness, post voiding residue and average flow rate were recorded pre-operatively. The post operative LUTS and sonogrsphic and uroflowmetric recordings were then assessed for analysis of overall voiding function. Though 48 patients were enrolled for study, the researcher could contact 27 patients for follow up assessment and another 6 could be contacted over telephone to record their post operative lower urinary tract symptoms. So symptom analysis was done for 33 patients while 27 follow up patients were checked for ultrasonographic and uroflowmetric findings too. The pre and post operative symptoms were made dichotomous as without any complaint and with complaints. These two variables were cross tabulated for assessing Lower Urinary Tract symptoms due to the effect of SAH. Finally the aggregated symptoms were put into table to see the proportional changes due to $\mathrm{SAH}$ intervention. The results were expressed as percentage, mean $\pm S D$ with their corresponding $\mathrm{p}$ values where needed. The urodynamic recordings were analyzed by Mann-Whitney U test while the LUTS were assessed by McNemar chi square test. A value less than 0.05 were considered significant.

\section{Results:}

The patients were from 35-52 years with a mean 42 and SD 4.08 years respectively. They were mostly $(n=46$, 95.83\%) premenopausal, had 3 children on average (Table I) got admitted mainly with the diagnosis of fibroid uterus (43.75\%) followed by DUB (18.75\%), PID (10.42\%) and endometriosis (8.33\%) while the rest constituted ovarian cyst, adenomyosis, post menopausal bleeding or combination of complaints. The common

Table-I

\begin{tabular}{lcc}
\multicolumn{3}{c}{ Background information of the respondents } \\
Variables & Mean \pm SD & Minimum-Maximum \\
\hline Age & $42.56 \pm 4.08$ & $35-52$ \\
Parity & $3.06 \pm 1.93$ & $0-7$ \\
Menstrual Status & Frequency & $\%$ \\
Premenopausal & 46 & 95.83 \\
Postmenopausal & 2 & 4.17 \\
Indication of operation & & \\
$\quad$ Fibroid uterus & 21 & 43.75 \\
$\quad$ DUB & 9 & 18.75 \\
$\quad$ PID & 5 & 10.42 \\
$\quad$ Endometriosis & 4 & 8.33 \\
$\quad$ Ovarian cyst & 3 & 6.25 \\
$\quad$ Combination: e"2 indications & 3 & 6.25 \\
$\quad$ Adenomyosis & 2 & 4.17 \\
Post-menopausal bleeding & 1 & 2.08 \\
\hline
\end{tabular}


voiding problems were urgency and stress incontinence (43.75\%) followed by 13 (27.08\%) frequency of micturition and dysuria, 6 (12.5\%) nocturia, 9 (18.75\%) urge incontinence, 16 (33.33\%) with sensation of residual urine, 15 (31.25\%) with stress on cough or vulsalva, and 26 (54.17\%) came with multiple problems.

Post operative LUTS was assessed with the pre operative one for 33 patients, shown in Table II, where 9 (27.27\%) complains of frequency was reduced to 3 (9.09\%) though it just missed the significance level. There were 6 pre operative complains of nocturia whereas no complains of nocturia was found post operatively. Complain of urgency was reduced significantly $(\mathrm{p}=0.02)$ from 21 (51.52\%) to 7 (21.21\%), urge incontinence significantly $(\mathrm{p}=0.03)$ reduced from $8(24.24 \%)$ to 2 (6.06\%), stress incontinence reduced significantly $(p=0.001)$ from $16(48.48 \%)$ to $2(6.06 \%)$, dysuria reduced reduced significantly $(\mathrm{p}=0.02)$ from 10
(30.30\%) to $2(6.06 \%)$, stress on cough or vulsalva reduced significantly $(\mathrm{p}=0.001)$ from $12(36.36 \%)$ to 1 (3.03\%), delayed bladder emptying reduced significantly ( $\mathrm{p}=0.04)$ from $13(48.48)$ to $4(12.12 \%)$ while sensation of residual urine reduced significantly $(\mathrm{p}=0.001)$ from13 (39.39\%) to 3 (9.09\%).

Table III shows the assessment of ultrasonic and uroflowmetric findingsof 27 follow up patients. Maximum bladder capacity was increased and bladder wall thickness was reduced significantly $(\mathrm{p}<0.001)$ with reduced average flow rate $(\mathrm{p}=0.04)$ while there was no significant reduction in post void residue.

The computed dichotomous pre and post operative complaints were assessed in Table IV and it was observed that there was nearly $82 \%$ patients who complained of voiding difficulty pre operatively which came down to $36.36 \%$ though the association was not significant due to small sample size only. Had the

Table-II

\begin{tabular}{|c|c|c|c|}
\hline \multicolumn{4}{|c|}{ Comparison of pre and post operative LUTS } \\
\hline Symptoms & Pre n (\%) & Post n (\%) & $\mathrm{p}$ \\
\hline Frequency & $9(27.27)$ & $3(9.09)$ & 0.07 \\
\hline Nocturia & $6(18.18)$ & $0(0)$ & - \\
\hline Urgency & $17(51.52)$ & $7(21.21)$ & 0.02 \\
\hline Urge incontinence & $8(24.24)$ & $2(6.06)$ & 0.03 \\
\hline Stress incontinence & $16(48.48)$ & $2(6.06)$ & 0.001 \\
\hline Dysuria & $10(30.30)$ & $2(6.06)$ & 0.02 \\
\hline Stress on cough or vulsalva & $12(36.36)$ & $1(3.03)$ & 0.001 \\
\hline Bladder emptying & 13 (39.39) & $4(12.12)$ & 0.04 \\
\hline Sensation of residual urine & $13(39.39)$ & $3(9.09)$ & 0.01 \\
\hline
\end{tabular}

Table-III

\begin{tabular}{lccc}
\multicolumn{2}{c}{ Comparison of pre and post operative urodynamic functions } \\
Variables & Mean \pm SD & Min -Max & p \\
\hline MBC-pre (27) & $423.30 \pm 113.39$ & $210-746$ & $<0.001$ \\
MBC-post (27) & $491.74 \pm 97.81$ & $300-700$ & $<0.001$ \\
BWT-pre (27) & $3.87 \pm 1.11$ & $1.8-5.9$ & 0.49 \\
BWT-post (27) & $3.71 \pm 1.07$ & $1.6-5.8$ & 0.04 \\
PVR-pre (27) & $7.41 \pm 7.47$ & $0-53$ & 0.04 \\
PVR-post (27) & $5.93 \pm 10.68$ & $2.2-27.3$ & $9.4-21.0$ \\
AFR-pre (17) & $17.15 \pm 5.74$ & $16.57 \pm 2.82$ & \\
AFR-post (17) &
\end{tabular}




\section{Table-IV}

\begin{tabular}{lcccc}
\multicolumn{5}{c}{ Comparison of overall pre and post operative urinary complaints } \\
& Post-operative & Pre operative & Total & p \\
& No (\%) & Yes (\%) & & 0.27 \\
\hline No & $5(15.15)$ & $16(48.49)$ & $21(63.64)$ & \\
Yes & $1(3.03)$ & $11(33.33)$ & $12(36.36)$ & \\
Total & $6(18.18)$ & $27(81.82)$ & $33(100.0)$ & \\
\hline
\end{tabular}

observed values been multiplied by a little more than 3 or in other words, had the sample size been more than 100 the association could reach significant level. So the table shows a huge reduction of nearly $46 \%$ post operatively.

\section{Discussion:}

Bangabandhu Sheikh Mujib Medical University is the central academic institution where SAH operations are performed on regular basis though the peri or postoperative morbidities especially the LUT functions are not well documented. Average $42.56 \pm 4.08$ years of the patients with parity ( $3 \pm 2)$ in this study corroborates with others $^{5,13,14}$ though some researchers ${ }^{12,15}$ recorded a higher score respectively. The complaints they came with are almost similar with El Toukhy ${ }^{17}$, Altman ${ }^{18}$ where almost all the researchers found fibroid uterus and DUB to be most prominent to decide for SAH.

There was decrease of urinary frequency in nearly $18 \%$, nocturia in $100 \%$, urgency in 30\%, urge incontinence in $18 \%$, stress incontinence in $42 \%$, dysuria in $24 \%$, stress on cough or vulsalva in $33 \%$, delayed bladder emptying in $27 \%$ and sensation of residual urine in $30 \%$ after SAH. The reduction of symptoms was statistically significant or nearly significant. Though previous studies $^{5-9}$ during the late 90 s observed considerable occurrences of voiding complains related with SAH and some ${ }^{10,11}$ found no relation whatsoever, later studies ${ }^{12,13,17,19-24}$ found significant improvement of urinary symptoms.

The ultrasonic and uroflowmetric findings did also improve in this study which conforms to the results ${ }^{17-}$ 24 of other studies. The study by Duru ${ }^{25}$ in 2012 showed a significant reduction of urinary symptoms after $\mathrm{SAH}$ though his study did not find any significant improvement of stress incontinence. Our study found an overall improvement in all types of complains and also the urodynamic studies except for post void residue. This might be due to some residual effect of the operation, which could be removed over time had we done the follow up further after 6 and 12 months.

Though complete urodynamic study could not be done in this study for confirmation of subjective LUTS and the severity of symptoms as well, the study urges the need of further investigation into a well documented search for pre-operative prevalence of LUTS in gynecological patients and whether those symptoms are related to the gynecologic diagnosis itself or just are associated. Long term follow up study is needed to see the impact of SAH on LUTs which can emulate future multi-center trial for effective management of lower urinary tract symptoms.

\section{References:}

1. Lambaudie E, Boukerreou M, Cosson M, Querleu D, Crepin G. Hysterectomy for Benign Lesions: Pre-operative and Early Post - operative Complications. 2000 May. Ann Chir. 125 (4): $340-5$.

2. Schofield LJ, Bennett A, Redman S, Walters WAW, Fisher LWS. Self Reported Long Term Outcomes of Hysterectomy. 1991. Int. JOG, 98: 1129-1136.

3. Hanley HG. The Late Urological Complications of Total Hysterectomy. 1969. Br. J Urol, 41: 682-4.

4. Tanagho EA. The Effect of Hysterectomy And Periurethral Surgery on Urethrovesical Function. 1980. In: Gynaelogical Urology and Urodynamics - Theory and Practice. Saltimore: Williams and Wilkins, 293.

5. Parys BT, Haylen BT, Hutton Jane L. Persons KF. The Effect of Simple Hysterectomy on Vesicourethral Function. 1989. Br. J. Urol, 64: 594 - 599.

6. Ralph G. Tamussino K, Lichtenegger W. Urological Complications After Radical Abdominal Hysterectomy for Cervical Cancer. 1988 Dec. Baillieres Clin Obstet Gynaecol, 2 (4): 943-52. 
7. Gin - Den Chen M. Long - Yaulin, Po - Hui Wang and H ong - Shen Lee. Urinary Tract Dysfunctions after Radical Hysterectomy for Cervical Cancer. 2002 May. Gynecologic Oncology. 85 (2): $292-97$.

8. Fishman IJ, Shabsigh R, Kaplan AL. Lower Urinary Tract Dysfunction After Radical Hysterectomy for Carcinoma of Cervix. 1986 Dec. Urology, 28 (6): 462 - 8.

9. Morgan JL, O`Connell HE, Mc Guire EJ. Is Intrinsic Sphincter Deficiency a Complication of Simple Hysterectomy? Sep 2000. J Urol, 164 (3 pt 1): 767 - 9.

10. Parazzini F, Chiaffarino F, Lavezzari M, Giambanco V. Risk Factors for Stress, Urge or Mixed Incontinence in Italy. 2003 October. BJOG, 110: 927-933.

11. Peyrat L, Haillot O, Bruyere F, Boutin JM, Bertrand P, Lanson Y. Prevalence and Risk Factors of Urinary Incontinence in Young and Middle-aged Women. 2002. BJU International, 89: 61-66.

12. Neumann G, Olsen PG, Hansen V, L Lauszus FF, Ljungstorm B, Rasmussen KL. The Short Term Prevalence of de novo Urinary Symptoms After Different Modes of Hysterectomy. 2003 Jan-Feb. Int.Urogynecol J Pelvic Floor Dysfunct. 15(1): 14 - 9; Discussion 19.

13. Langer R, Newman M., Ron - EL R., Golan A., Bukovsky I. and Caspi E. The Effect of Total Abdominal Hysterectomy on Bladder Function in Asymptomatic Women. 1989 Aug. Obstet Gynecol. 74 (2): 205 - 7.

14. Virtanen H, Makinen J, Tenho T. Kiilholma P, Pitkanen Y. and. Hirvonen T. Effects of Abdominal Hysterectomy on Urinary and Sexual Symptoms. 1993. Br. J. Urol, 72: $868-72$.

15. Prasad M, Sadhukhan M, Tom B, Al - Taher H. The Effect of Hysterectomy on Urinary Symptoms and Residual Bladder Volume. 2002 Sep. J Obstet Gynaeco, 22 (5): 544 - 7.

16. Kjerulff KH; Lanngenberg PW; Greenaway L; Uman J; Harvey LA.. Urinary Incontinence and Hysterectomy in a Large
Prospective Cohort. Study in American Women. 2002 May. J Urol, 167(5): 2088 - 92.

17. El-toukhy TA, Hefni M, Savies A, Mahadevan S. The Effect of Different Types of Hysterectomy on Urinary and Sexual Function: a Prospective Study. 2004 Jun. J Obstet Gynaecol, 24 (4): $420-5$.

18. Altman D, Lopez A, Falconer C, Zetterstrom J. The Impact of Hysterectomy on Lower Urinary Tract Symptoms. 2003 Dec. Int.Urogynecol J Pelvic Floor Dysfunct, 14 (6) : 418-23.

19. Long CY, Hsu SC, Wu TP, Hsu YS, Su JH. Effect of Laparoscopic Hysterectomy on Bladder Neck and Urinary Symptoms. Feb 2003. AustNZ J Obstet Gynaecol, 43 (1): 65-9.

20. Brown JS, Sawaya G, Thom DH, Grady D. Hysterectomy and Urinary Incontinence: a systematic review. 2000. Lancet, 356: 535-539.

21. Jones MD, Jarvis GJ, McNamara HM. Adverse Urinary Symptoms after Total Abdominal Hysterectomy - Fact or Fiction? 1991. Br. J. Urol, 67, 295-297.

22. Wake CR. The Immediate Effect of Abdominal Hysterectomy on Intravesical Pressure and Detrusor Activity. 1980 Oct. Br. J Obstet Gynaeco, 87: 901 - 902.

23. Thakar Ranee, Ayers Susan, Clarkson Peter, Stanton Stuart, Manyonda Isaac. Outcomes after Total Versus Subtotal Abdominal Hysterectomy. N Engl J Med, 347 (17); Oct 2002: 1318-1325.

24. Samir ME, Yousry MMA, Sherif MK, Mohamed EY, Ahmed AE. Total versus subtotal abdominal hysterectomy influence on the urinary bladder function. Bull Alex Fac Med, 45 (1); 2009: 47-52.

25. Duru C, Jha S, Lashen H. Urodynamic outcomes after hysterectomy for benign conditions: a systematic review and meta analysis. Obstetrical and Gynecological Survey, 67 (1); Jan 2012: 45-54. 